\title{
TERT promoter hotspot mutations in breast cancer
}

\author{
Tatsunori Shimoi $^{1,2} \cdot$ Masayuki Yoshida $^{3} \cdot$ Yuka Kitamura $^{1} \cdot$ Tomomi Yoshino $^{1} \cdot$ Asuka Kawachi $^{1}$. \\ Akihiko Shimomura ${ }^{1} \cdot$ Emi Noguchi $^{1} \cdot$ Mayu Yunokawa ${ }^{1} \cdot$ Kan Yonemori $^{1} \cdot$ Chikako Shimizu $^{1} \cdot$ Takayuki Kinoshita $^{4}$. \\ Koichi Ichimura ${ }^{5} \cdot$ Takahiro Fukuda $^{2,6} \cdot$ Yasuhiro Fujiwara $^{1} \cdot$ Kenji Tamura $^{1}$
}

Received: 27 September 2017 / Accepted: 29 November 2017 / Published online: 8 December 2017

(c) The Author(s) 2017. This article is an open access publication

\begin{abstract}
Background Telomerase reverse transcriptase (TERT) promoter mutations have been discovered in solid and hematological malignancies, where they reflect TERT activation and cell-cycle progression. In melanoma, glioma, and thyroid cancers, TERT promoter mutations are associated with a poor prognosis. However, no studies have evaluated the prevalence and prognostic significance of TERT promoter mutations in breast cancer.

Methods We analyzed TERT promoter hotspot mutations (C228T and C250T) using direct sequencing of DNA from 319 tumor tissues. We also collected clinical data from cases that were positive for TERT promoter mutations.

Results We detected TERT promoter mutations in three ( $0.9 \%)$ of the 319 cases. Two patients had hormone receptor-positive and human epidermal growth factor receptor 2-negative cancer, while the third patient had triple-negative cancer. All three patients had initially been diagnosed with operable breast cancer and undergone surgical treatment. The relapse-free survivals of these patients were 83,226 , and 270 months, respectively. The mutations were C250T in the triple-negative cancer case and $\mathrm{C} 228 \mathrm{~T}$ in the remaining two cases.

Conclusion Given the rarity of TERT promoter mutations, further studies are needed to confirm their prognostic significance in breast cancer cases.
\end{abstract}

Keywords Breast cancer $\cdot$ Telomerase reverse transcriptase $\cdot$ TERT promoter mutation

Kenji Tamura

ketamura@ncc.go.jp

1 Department of Breast and Medical Oncology, National Cancer Center Hospital, 5-1-1 Tsukiji, Chuo-ku, Tokyo 104-0045, Japan

2 Graduate School of Medicine, Course of Advanced Clinical Research of Cancer, Juntendo University, Tokyo, Japan

3 Department of Pathology and Clinical Laboratories, National Cancer Center Hospital, Tokyo, Japan

4 Department of Breast Surgery, National Cancer Center Hospital, Tokyo, Japan

5 Division of Brain Tumor Translational Research, National Cancer Center, Tokyo, Japan

6 Department of Hematopoietic Stem Cell Transplantation, National Cancer Center Hospital, Tokyo, Japan

\section{Introduction}

Breast cancer is a common cancer and the leading global cause of cancer-related mortality among women [1]. In addition, breast cancer is a heterogeneous condition that is categorized into four subtypes according to pathological review, hormone receptor status, and human epidermal growth factor receptor 2 (HER2) status. Furthermore, using wholegenome sequencing, numerous somatic and driver mutations have been identified in breast cancer [2]. This information has allowed physicians to stratify patients according to their tumor's molecular characteristics and select appropriate therapies. Recent clinical trials have indicated that mutations in the genes for phosphatidylinositol-4,5-bisphosphate 3-kinase catalytic subunit alpha $(P I K 3 C A)$ and RAC-alpha serine/threonine-protein kinase $(A K T 1)$ may predict the response to PI3 K and AKT inhibitors, respectively [3-5].

Telomerase is a DNA polymerase that maintains the length of telomeres at the end of chromosomes. Its activity is relatively high in stem cells and is downregulated in 
normal somatic cells. However, genetic mutations can also affect the non-coding regulatory region of the telomerase reverse transcriptase (TERT) gene's promoter, and telomerase can be activated by mutations in the TERT promoter. Many malignant tumor cells have TERT expression or telomerase activity, with $>90 \%$ of breast cancer cases having telomerase activity [6].

In 2013, somatic hotspot mutations in the promoter region of TERT were reported among patients with melanoma $[7,8]$. In addition to these two common hotspots identified on chromosome 5: 1,295,228 C > T (C228T) and $1,295,250 \mathrm{C}>\mathrm{T}(\mathrm{C} 250 \mathrm{~T})$, the tandem mutations of $1,295,228 / 1,295,229 \mathrm{CC}>\mathrm{TT}(\mathrm{C} 228 \mathrm{~T} / \mathrm{C} 229 \mathrm{~T})$ and $1,295,242 / 1,295,243 \mathrm{CC}>\mathrm{TT}$ (C242T/C243T) have also been reported in melanoma with TERT promoter mutation. In a previous report, mutation frequencies for C228T, C250T, C228T/C229T and C242T/C243T in melanoma cell lines were 46/168 (27\%), 64/168 (38\%), 7/168 (4.2\%) and $8 / 168$ (4.8\%), respectively. On the contrary, no mutation sites other than C228T and C250T have been reported in glioma. In one large retrospective cohort, the mutation frequencies of C228T and C250T in primary glioblastoma with TERT promoter mutation were 123/256 (48\%) and $56 / 256(22 \%)$, respectively [13]. Since the first report of melanoma, $>30$ types of tumors have been found to contain TERT promoter mutations, hepatocellular carcinoma (41\%), thyroid cancer (11-43\%), ovarian clear cell carcinoma (16\%), bladder cancer (63\%), and phyllodes tumors of the breast (65\%) [9-11]. In these types of cancer other than melanoma, C228T and C250T were also hotspots of TERT promoter mutations, in which C228T is more dominant than C250T. These hotspot mutations are associated with a poor prognosis $[7,12,14,15]$. However, to the best of our knowledge, no reports have evaluated the prevalence and prognostic significance of TERT promoter mutations in human breast cancer. Therefore, the present study aimed to provide information regarding TERT promoter mutations in samples from human breast cancer.

\section{Materials and methods}

We retrospectively evaluated 319 breast cancer specimens (125 frozen specimens and 194 formalin-fixed paraffinembedded [FFPE] specimens) that were provided by the National Cancer Center Biobank of Japan and had been obtained between January 1983 and November 2015. Three patients had metachronous breast cancer and we included all of their samples in this study. We extracted DNA from the frozen specimens using the QIAamp DNA FFPE tissue kit (QIAGEN, Tokyo) and from the FFPE specimens using the QIAamp DNA Mini Kit (QIAGEN, Tokyo), according to the manufacturer's recommendations. The TERT promoter mutations (C228T and C250T) were identified using direct sequencing according to the previously reported methods $[12,13]$, and the direct sequencing was performed by FASMAC (Tokyo, Japan). The forward primer's sequence was 5'-gtaaaacgacggccagcaggaaacagctatgacccagctccgcctcctccg- $3^{\prime}$ and the reverse primer's sequence was $5^{\prime}$-gctgcctgaaactcgcgcc- $3^{\prime}$. Mutations in the PIK3CA gene (E542K, E545K, or H1047R) were detected using quenching probe system by the i-densy IS-5320 system (ARKRAY Inc., Kyoto, Japan) [16].

Estrogen receptor (ER) and progesterone receptor (PgR) were classified positive if $\geq 10 \%$ of tumor cells demonstrated positive nuclear staining for ER or PgR, respectively [17]. HER2 positivity was classified according to the recommendation of the American Society of Clinical Oncology/ College of American Pathologists guidelines [18]. Hormone receptor positive was defined as positive for ER or PgR. Histological and nuclear grades were reported according to previously reported criteria $[19,20]$.

Relapse-free survival was defined as the time between the day of diagnosis and disease progression or last follow-up. Overall survival was defined as the time between the day of diagnosis and the day of death or last follow-up.

This study's retrospective protocol was approved by the National Cancer Center Institutional Review Board (No. 2014-092). Written informed consent was not obtained from the patients. The results of this study have been published on our hospital's web page.

\section{Results}

Sequencing was successful for all 319 specimens, and we detected TERT promoter mutations in three samples $(0.9 \%)$. The TERT promoter mutations were only detected in the tumor tissue DNA and were not detected in the three patients' normal tissue DNA. The three patients' characteristics are shown in Table 1. All patients were women who had experienced a relatively late relapse, after undergoing surgery because of an early diagnosis of breast cancer. Two patients demonstrated relapse-free survivals of $>200$ months. The histological results were invasive ductal carcinoma in two cases and invasive lobular carcinoma in one case. Two patients had hormone receptor-positive and HER2-negative breast cancer, while one patient had triple-negative breast cancer (TNBC). C250T mutations were noted in the TNBC case and $\mathrm{C} 228 \mathrm{~T}$ in the two hormone receptor-positive cases (Fig. 1). Two of these patients had mutations in the PIK3CA kinase domain (H1047R) (Table 1). 
Table 1 The characteristics of the three breast cancer patients with TERT promoter mutations

\begin{tabular}{|c|c|c|c|}
\hline & Case 1 & Case 2 & Case 3 \\
\hline Age, years & 59 & 41 & 46 \\
\hline Sex & Female & Female & Female \\
\hline Initial stage & $1 \mathrm{~A}$ & ND & $2 \mathrm{~A}$ \\
\hline Histology & IDC & IDC & ILC \\
\hline Histological grade & 2 & 2 & 1 \\
\hline Nuclear grade & 1 & 2 & 1 \\
\hline Estrogen receptor (AS) & Negative (0) & Positive (8) & Positive (8) \\
\hline $\begin{array}{l}\text { Progesterone receptor } \\
\text { (AS) }\end{array}$ & Negative (0) & Positive (8) & Positive (8) \\
\hline HER2 status (IHC score) & Negative (0) & Negative (0) & Negative $(1+)$ \\
\hline $\begin{array}{l}\text { PIK3CA hotspot muta- } \\
\text { tion }\end{array}$ & H1047R & Negative & H1047R \\
\hline$T E R T$ hotspot mutation & $\mathrm{C} 250 \mathrm{~T}$ & $\mathrm{C} 228 \mathrm{~T}$ & $\mathrm{C} 228 \mathrm{~T}$ \\
\hline $\begin{array}{l}\text { Relapse-free survival, } \\
\text { months }\end{array}$ & 83 & 226 & 270 \\
\hline Overall survival, months & 100 & 446 & 300 \\
\hline Status & Alive & Alive & Alive \\
\hline
\end{tabular}

$N D$ no data, $I D C$ invasive ductal carcinoma, ILC invasive lobular carcinoma, AS Allred score, HER2 human epidermal growth factor receptor $2, I H C$ immunohistochemistry

\section{Discussion}

This is the first detailed report regarding TERT promoter mutations in human breast cancer, and we identified TERT promoter mutations in three $(0.9 \%)$ of 319 samples. However, a previous report identified two cases with TERT promoter mutations among eight human breast cancer cell lines (25\%) [12]. Nevertheless, another report failed to detect TERT promoter hotspot mutations in 88 breast cancer samples [10]. In the present study, we found that two of the three samples with TERT promoter mutations also had PIK3CA kinase domain mutations. In ovarian cancer, TERT promoter mutation and PIK3CA mutation are considered mutually exclusive [21], whereas this coexistence is reported in other carcinomas [22, 23]. Given that PIK3CA mutation is a relatively common mutation in breast cancer, we investigated the coexistence of these mutations. Interestingly, PIK3CA mutations only exist in approximately $30 \%$ of patients with hormone receptorpositive breast cancer and in approximately $10-20 \%$ of TNBC cases. Moreover, TERT promoter mutations coexist with PIK3CA mutations in $12 \%$ of anaplastic thyroid cancers [22], but only in $7.5 \%$ of gliomas [23]. Thus, it is possible that a relationship exists between TERT promoter and PIK3CA kinase domain mutations.

$T E R T$ promoter mutations occur during the early stage of glioma or thyroid cancers and are associated with a poor prognosis among patients with melanoma, glioma, and thyroid cancer [22, 24-26]. Moreover, a recent study showed that the prognostic effect of TERT promoter mutation was different for each melanoma subtype [27]. Our study has few samples; hence, it is difficult to be definite about the prognosis. However, we could not conclude that the TERT promoter mutation was a poor prognostic factor based on our results.

It would have been indeed useful to analyze telomerase activity and/or TERT expression in these tumors. However, fresh-frozen tissues would be required to assess either of them. Unfortunately, materials available for this study were only FFPE specimen from the biopsy, and no frozen tissues were preserved. We could not extract enough RNA from
Fig. 1 TERT promoter mutations in the three breast cancer cases. Sanger sequencing of the tumor tissue DNA revealed C250T (case 1) and C228T (cases 2 and 3) somatic mutations in the TERT promoter of the three breast cancer patients. All patients demonstrated TERT promoter mutations only in their tumor tissue DNA and not in the normal tissue DNA. Positive result for a TERT hotspot mutation is indicated by the corresponding yellow box

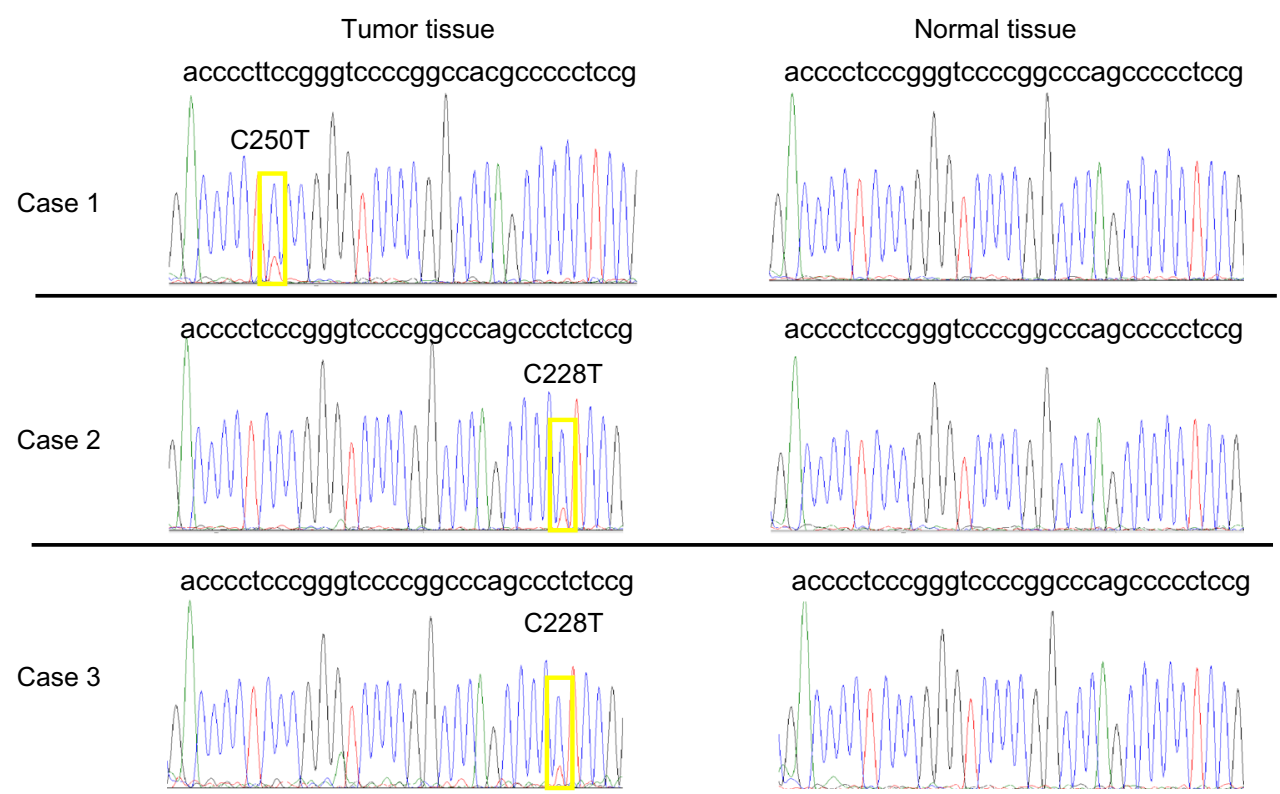


the FFPE tissue samples, and no antibody against TERT for immunohistochemistry is currently available. Therefore, it was impossible to examine telomerase activity or TERT expression. In most previous reports, TERT expression was significantly elevated in cases with unified hotspot mutation compared with the wild-type cases [10, 12-14, 21, 25, 28, 29]. We believe our mutated tumors had elevated TERT expression.

Further studies are needed to clarify our findings. We consider two types of prospective cohort studies to investigate the prognostic importance and predictive factor in breast cancer. In one large-scale cohort study, which include prognostic factors of breast cancer such as stage, age, subtype, grade, or other biomarkers with TERT promoter mutation, we will be able to investigate whether the TERT promoter mutation is a prognostic factor. On the contrary, a study on ovarian cancer reported that a high TERT expression is a predictive factor for the effect of eribulin mesylate [30]. Therefore, another large-scale cohort study may also consider whether the TERT promoter mutation is a predictive factor of the effect of an anticancer agent, especially eribulin mesylate.

In conclusion, we have demonstrated the presence of $T E R T$ promoter mutation in breast cancer.

Acknowledgements We thank Nao Nakamura and Rumi Koyama for providing secretarial support during this study. The National Cancer Center Biobank is supported by the Japanese National Cancer Center Research and Development Fund. We thank the individuals whose data and specimens were used for the analyses.

\section{Compliance with ethical standards}

Ethical approval Ethical approval is in accordance with the Declaration of Helsinki.

Funding This work was supported by funds for Cancer Research and Development [23-B-15] from the Japan Ministry of Health, Labour and Welfare.

Conflicts of interest The authors have declared no conflicts of interest.

Open Access This article is distributed under the terms of the Creative Commons Attribution 4.0 International License (http://creativecommons.org/licenses/by/4.0/), which permits unrestricted use, distribution, and reproduction in any medium, provided you give appropriate credit to the original author(s) and the source, provide a link to the Creative Commons license, and indicate if changes were made.

\section{References}

1. Siegel R, Miller K, Jemal A. Cancer statistics, 2015. CA Cancer J Clin. 2015;65:5-29.
2. Nik-Zainal S, Davies H, Staaf J, Ramakrishna M, Glodzik D, Zou X, Martincorena I, et al. Landscape of somatic mutations in 560 breast cancer whole-genome sequences. Nature. 2016;534:47-54.

3. Arteaga C. Benefit mixed with caution for buparlisib. Cancer Discov. 2017;7:121.

4. Davies BR, Guan N, Logie A, Crafter C, Hanson L, Jacobs V, et al. Tumors with AKT1 E17 K mutations are rational targets for single agent or combination therapy with AKT inhibitors. Mol Cancer Ther. 2015;14:2441-51.

5. Tamura K, Hashimoto J, Tanabe Y, Kodaira M, Yonemori K, Seto T, et al. Safety and tolerability of AZD5363 in Japanese patients with advanced solid tumors. Cancer Chemother Pharmacol. 2016;77:787-95.

6. Herbert BS, Wright WE, Shay JW. Telomerase and breast cancer. Breast Cancer Res. 2001;3:146-9.

7. Huang FW, Hodis E, Xu MJ, Kryukov GV, Chin L, Garraway LA. Highly recurrent TERT promoter mutations in human melanoma. Science. 2013;339:957-9.

8. Horn S, Figl A, Rachakonda PS, Fischer C, Sucker A, Gast A, et al. TERT promoter mutations in familial and sporadic melanoma. Science. 2013;339:959-61.

9. Liu T, Yuan X, Xu D. Cancer-specific telomerase reverse transcriptase (Tert) promoter mutations: Biological and clinical implications. Genes (Basel). 2016;7(7):38.

10. Killela PJ, Reitman ZJ, Jiao Y, Bettegowda C, Agrawal N, Diaz LA Jr, et al. TERT promoter mutations occur frequently in gliomas and a subset of tumors derived from cells with low rates of self-renewal. Proc Natl Acad Sci USA. 2013;110:6021-6.

11. Yoshida M, Ogawa R, Yoshida H, Maeshima A, Kanai Y, Kinoshita $\mathrm{T}$, et al. TERT promoter mutations are frequent and show association with MED12 mutations in phyllodes tumors of the breast. Br J Cancer. 2015;113:1244-8.

12. Vinagre J, Almeida A, Pópulo H, Batista R, Lyra J, Pinto V, et al. Frequency of TERT promoter mutations in human cancers. Nat Commun. 2013;4:2185.

13. Arita H, Narita Y, Fukushima S, Tateishi K, Matsushita Y, Yoshida A, et al. Upregulating mutations in the TERT promoter commonly occur in adult malignant gliomas and are strongly associated with total 1p19q loss. Acta Neuropathol. 2013;126:267-76.

14. Arita H, Narita Y, Takami H, Fukushima S, Matsushita Y, Yoshida A, et al. TERT promoter mutations rather than methylation are the main mechanism for TERT upregulation in adult gliomas. Acta Neuropathol. 2013;126:939-41.

15. Liu C, Liu Z, Chen T, Zeng W, Guo Y, Huang T. TERT promoter mutation and its association with clinicopathological features and prognosis of papillary thyroid cancer: a meta-analysis. Sci Rep. 2016;6:36990.

16. Nakamura T, Sueoka-Aragane N, Iwanaga K, Sato A, Komiya $\mathrm{K}$, Kobayashi N, et al. Application of a highly sensitive detection system for epidermal growth factor receptor mutations in plasma DNA. J Thorac Oncol. 2012;7:1369-81.

17. Allred DC, Harvey JM, Berardo M, Clark GM. Prognostic and predictive factors in breast cancer by immunohistochemical analysis. Mod Pathol. 1998;11:155-68.

18. Wolff AC, Hammond MEH, Schwartz JN, Hagerty KL, Allred DC, Cote RJ, et al. American Society of Clinical Oncology/College of American Pathologists guideline recommendations for human epidermal growth factor receptor 2 testing in breast cancer. J Clin Oncol. 2007;25:118-45.

19. Tsuda H, Akiyama F, Kurosumi M, Sakamoto G, Watanabe T. Establishment of histological criteria for high-risk node-negative breast carcinoma for a multi-institutional randomized clinical trial of adjuvant therapy. Jpn J Clin Oncol. 1998;28:486-91.

20. Elston CW, Ellis IO. Pathological prognostic factors in breast cancer. I. The value of histological grade in breast cancer: experience 
from a large study with long-term follow-up. Histopathology. 1991;19:403-10.

21. Wu RC, Ayhan A, Maeda D, Kim KR, Clarke BA, Shaw P, et al. Frequent somatic mutations of the telomerase reverse transcriptase promoter in ovarian clear cell carcinoma but not in other major types of gynaecological malignancy. J Pathol. 2014;232:473-81.

22. Tiedje V, Ting S, Herold T, Synoracki S, Latteyer S, Moeller LC, et al. NGS based identification of mutational hotspots for targeted therapy in anaplastic thyroid carcinoma. Oncotarget. 2017;8:42613-20.

23. Zacher A, Kaulich K, Stepanow S, Wolter M, Köhrer K, Felsberg $\mathrm{J}$, et al. Molecular diagnostics of gliomas using next generation sequencing of a glioma-tailored gene panel. Brain Pathol. 2017;27:146-59.

24. Griewank KG, Murali R, Puig-Butille JA, Schilling B, Livingstone E, Potrony M, et al. TERT promoter mutation status as an independent prognostic factor in cutaneous melanoma. J Natl Cancer Inst. 2014;106(9). http://doi.org/10.1093/jnci/dju246.

25. Xing M, Liu R, Liu X, Murugan AK, Zhu G, Zeiger MA, et al. BRAF V600E and TERT promoter mutations cooperatively identify the most aggressive papillary thyroid cancer with highest recurrence. J Clin Oncol. 2014;32:2718-26.

26. Simon M, Hosen I, Gousias K, Rachakonda S, Heidenreich B, Gessi M, et al. TERT promoter mutations: a novel independent prognostic factor in primary glioblastomas. Neuro Oncol. 2015;17:45-52.

27. Roh MR, Park KH, Chung KY, Shin SJ, Rha SY, Tsao H. Telomerase reverse transcriptase (TERT) promoter mutations in Korean melanoma patients. Am J Cancer Res. 2017;7:134-8.

28. Chen C, Han S, Meng L, Li Z, Zhang X, Wu A. TERT promoter mutations lead to high transcriptional activity under hypoxia and temozolomide treatment and predict poor prognosis in gliomas. PLoS One. 2014;9:e100297.

29. Wang N, Liu T, Sofiadis A, Juhlin CC, Zedenius J, Höög A, et al. TERT promoter mutation as an early genetic event activating telomerase in follicular thyroid adenoma (FTA) and atypical FTA. Cancer. 2014;120:2965-79.

30. Yamaguchi S, Maida Y, Yasukawa M, Kato T, Yoshida M, Masutomi K. Eribulin mesylate targets human telomerase reverse transcriptase in ovarian cancer cells. PLoS One. 2014;9:e112438. 